\title{
Trends in cancer mortality in Mexico, 1970-1999
}

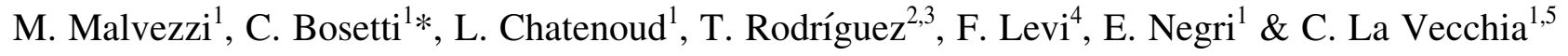 \\ ${ }^{1}$ Istituto di Ricerche Farmacologiche 'Mario Negri', Milan; ${ }^{2}$ Universidad Pùblica de Navarra, Departamento de Ciencias de la Salud, Pamplona, Spain; \\ ${ }^{3}$ Universidad Autonoma de San Luis Potosí, Facultad de Medicina, San Luis Potosí, Mexico; ${ }^{4}$ Registre Vaudois des Tumeurs, Institut Universitaire de Médecine \\ Sociale et Préventive, Lausanne, Switzerland; ${ }^{5}$ Istituto di Statistica Medica e Biometria, Università degli Studi di Milano, Milan, Italy
}

Received 22 March 2004; revised 7 June 2004; accepted 14 June 2004

\begin{abstract}
Background: Few data on cancer mortality have been published for Mexico over the last few decades. It is therefore of interest to conduct a systematic and updated analysis of cancer mortality in this country.

Patients and methods: Age-standardised (world population) mortality rates, at all ages and truncated at age 35-64 years, from major cancers and all cancers combined were computed on the basis of certified deaths derived from the World Health Organization database for the period 1970-99.

Results: Mortality rates for all neoplasms showed an upward trend in men of all ages (from $58.2 / 100000$ in $1970-74$ to $87.1 / 100000$ in 1995-99) and in middle-aged men (from 76.1 to $93.7 / 100000$, respectively). This reflects the rise until the early 1990s in lung cancer mortality (from $8.1 / 100000$ in 1970-74 to 15.6/100000 in 1995-99) and prostate cancer (from 5.5 to 12.2/100000, respectively). In women, overall mortality rates showed an increase between the early 1970s (75.4/100 000) and the late 1990 s $(82.3 / 100000)$. Total cancer mortality rates remained low, however, compared with other American countries (e.g. 153.3/100000 men and 108.6/100000 women in 1999 in the United States). Truncated rates were stable (126.5/100000 in 1970-74 and 125.8/100000 in 1995-99), although they were much higher than overall rates, reflecting exceedingly high rates for uterine (mostly cervical) cancer mortality in middle-aged women (29.5/100 000 in 1995-99).

Conclusions: Total cancer mortality in Mexico has remained comparably low on a worldwide scale, and the upward trends in mortality rates for lung and other tobacco-related neoplasms have tended to level off over the last decade. However, steady rises have been observed for other major cancers, including prostate and breast. Cervical cancer remains a major health problem in women.
\end{abstract}

Key words: Mexico, mortality, neoplasms

\section{Introduction}

Data and statistics on cancer mortality over the last few decades are available for most developed countries in Europe, North America, Australia and Japan [1], but fewer data have been published for Latin America, including Mexico.

Mexico has a territorial extension of $\sim 2$ million $\mathrm{km}^{2}$ and $\sim 97$ million inhabitants [2]. Information on major causes of death has been available since 1922 [3] and mortality data have been provided to the World Health Organization (WHO) since 1955 . Death certificates are routinely signed by a doctor, checked at state level, and finally registered and collected in a repository at the National Institute of Statistics, Geography and Informatics.

*Correspondence to: Dr Cristina Bosetti, Laboratorio di Epidemiologia, Istituto di Ricerche Farmacologiche 'Mario Negri', Via Eritrea 62, 20157 Milan, Italy. Tel: +39-02-39014-526; Fax: +39-02-33200231;

E-mail: bosetti@marionegri.it
Mexican data on cancer mortality up to 1986 have been considered in a summary report of cancer mortality in the Americas [4]. Among the interesting aspects of this report, low mortality rates were registered for several major cancer sites, including mouth and pharynx, oesophagus, colorectum, lung, breast and prostate, and high rates were registered for cancer of the (cervix) uteri [5]. Gastric cancer rates were appreciably higher than in North America, although they were relatively low compared with other Latin American countries. Steady upward trends were observed for cancer of the lung and for several other tobacco-related neoplasms, mainly in men [6], and also for cancers of the female breast. In contrast, stomach cancer mortality showed an appreciable downward trend, and colorectal cancer rates remained low over time [4].

Other analyses on mortality from selected cancers in Mexico for the period 1980-1995 reported increasing trends for cancers of the lung [7], breast [8], colorectum [9], prostate [10] and stomach [11]. Inconsistent trends were reported for cervical cancer $[12-14]$. 
It is therefore of interest to conduct a systematic and updated analysis of cancer mortality in this country. The availability of such data is of importance and interest for descriptive epidemiology, as well as for the definition of priorities in public health policies.

\section{Patients and methods}

Certified deaths for the six quinquennia considered (from 1970-74 to 1995-99), stratified for sex and 5-year age groups, from 13 selected cancer sites and for total cancer, were derived from the WHO database [15]. Data for 1984 were unavailable for all neoplasms. Mortality data for ovarian and testicular cancers were unavailable for 1970 and 1975-97, and bladder cancer data were unavailable for 1970 and 1975-78. No extrapolations were made for missing data.

During the calendar periods considered, three different revisions of the International Classification of Diseases (ICD) were used [16-18]. Classification of cancer deaths was thus recoded for all calendar periods according to the IX Revision of the ICD [17, 19]. To reduce classification problems and improve comparability of data, we pooled all intestinal cancers (chiefly colon and rectum), all uterine cancers (cervix and corpus) and all leukaemias. No reliable data were available for several rarer cancers (i.e. gallbladder, soft tissue sarcomas, lymphomas and thyroid) and a few other sites (i.e. pancreas, kidney and brain), which involve major difficulties in diagnosis and certification [20]. Data for liver, bone and skin cancer were excluded from the present analysis due to potential problems with reliability of certification.

Estimates of the resident population, based on official censuses, were obtained from the same WHO database for the period 1970-95 (excluding 1984) [15] and from the Pan American Health Organization (PAHO) [21] for 1996-99. Since the PAHO database provided only data for the total population, the 5-year age groups were estimated by interpolating from the 1995 WHO distribution. From the matrices of certified deaths and resident population, age-specific rates for each 5-year age group and calendar period were computed. Age-standardised rates, at all ages and truncated at age 35-64 years, were computed by the direct method on the basis of the world standard population [22]. Since this is essentially a descriptive report, no inference was made on the statistical significance of rates and trends.

\section{Results}

For each cancer site, two tables are given, which display world-standardised mortality rates for both men and women of all ages (Table 1) and truncated at age 35-64 years (Table 2) for the quinquennia 1970-74 and 1995-99, and the corresponding percentage changes.

Figure 1 shows the trends in world-standardised mortality rates for each cancer site (for men and women, at all ages and truncated) for the calendar period 1970-99. Overall mortality from cancers of the mouth and pharynx in men increased from $1.36 / 100000$ in $1970-74$ to $1.85 / 100000$ in $1985-89$, and levelled off thereafter to reach a value of 1.79 in 1995-99. A similar trend was found in middle-aged men (35-64 years), whose rates varied from $1.95 / 100000$ in $1970-74$ to $2.35 / 100000$ in 1995-99. Mortality from cancer of the mouth and pharynx was much lower in women of all ages, and showed a slight upward trend until the mid-1980s (0.59/100000 in 1970-74 and $0.74 / 100000$ in 1985-89), which then levelled off during the 1990s (0.69/100000 in 1995-99). Similarly, in middle-aged women, rates increased from $0.80 / 100000$ in $1970-74$ to $0.89 / 100000$ in $1995-99$.

A similar pattern in mortality trends was observed for oesophageal cancer, the overall mortality of which in men increased until the late 1980s (from 1.52/100000 in 1970-74 to $1.94 / 100000$ in 1985-89), and then stabilised at a value of $1.81 / 100000$ in 1995-99. In men aged 35-64 years, rates showed no clear trend, varying from 2.08/100 000 in 1970-74 to $2.05 / 100000$ in $1995-99$. Oesophageal cancer mortality in women was lower, and showed a slight decrease over time.

Table 1. Age-standardised (world population) death rates (per 100 000) from selected cancers or groups of cancers in Mexico, 1970-99

\begin{tabular}{|c|c|c|c|c|c|c|c|}
\hline \multirow[t]{2}{*}{ Cancer site } & \multirow[t]{2}{*}{ ICD IX } & \multicolumn{3}{|l|}{ Men } & \multicolumn{3}{|l|}{ Women } \\
\hline & & $1970-74$ & $1995-99$ & $\begin{array}{l}\text { Percent change } \\
95-99 / 70-74\end{array}$ & $1970-74$ & $1995-99$ & $\begin{array}{l}\text { Percent change } \\
95-99 / 70-74\end{array}$ \\
\hline Mounth or pharynx & $140-149$ & 1.36 & 1.79 & 31.96 & 0.59 & 0.69 & 16.58 \\
\hline Oesophagus & 150 & 1.52 & 1.81 & 18.85 & 0.75 & 0.66 & -11.50 \\
\hline Stomach & 151 & 9.90 & 9.17 & -7.42 & 8.70 & 6.58 & -24.36 \\
\hline Intestines, chiefly colon and rectum & $152-154,159.0$ & 2.64 & 3.83 & 45.28 & 3.24 & 3.42 & 5.40 \\
\hline Larynx & 161 & 2.05 & 2.44 & 18.95 & 0.58 & 0.42 & -27.38 \\
\hline Lung & 162 & 8.14 & 15.55 & 91.00 & 4.05 & 5.99 & 47.90 \\
\hline Breast & 174 & - & - & - & 5.22 & 9.65 & 84.90 \\
\hline Uterus, cervix and corpus & $179-182$ & - & - & - & 19.09 & 15.35 & -19.59 \\
\hline Ovary and other uterine adnexa & 183 & - & - & - & 1.81 & 3.41 & 88.74 \\
\hline Prostate & 185 & 5.47 & 12.24 & 124.03 & - & - & - \\
\hline Testis & 186 & 0.38 & 0.68 & 79.51 & - & - & - \\
\hline Bladder & 188 & 0.85 & 1.42 & 67.20 & 0.39 & 0.57 & 45.17 \\
\hline Leukaemias & $204-208$ & 2.41 & 4.03 & 67.45 & 2.13 & 3.28 & 54.13 \\
\hline All neoplasms, benign and malignant & $140-239$ & 58.18 & 87.14 & 49.77 & 75.43 & 82.28 & 9.09 \\
\hline
\end{tabular}


Table 2. Age-standardised (world population) truncated (35-64 years) death rates (per 100 000) from selected cancers or groups of cancers in Mexico, 1970-99

\begin{tabular}{|c|c|c|c|c|c|c|c|}
\hline \multirow[t]{2}{*}{ Cancer site } & \multirow[t]{2}{*}{ ICD IX } & \multicolumn{3}{|l|}{ Men } & \multicolumn{3}{|l|}{ Women } \\
\hline & & $1970-74$ & $1995-99$ & $\begin{array}{l}\text { Percent change } \\
95-99 / 70-74\end{array}$ & $1970-74$ & $1995-99$ & $\begin{array}{l}\text { Percent change } \\
95-99 / 70-74\end{array}$ \\
\hline Mounth or pharynx & $140-149$ & 1.95 & 2.35 & 20.26 & 0.80 & 0.89 & 10.98 \\
\hline Oesophagus & 150 & 2.08 & 2.05 & -1.16 & 1.01 & 0.77 & -23.12 \\
\hline Stomach & 151 & 13.01 & 10.82 & -16.82 & 11.04 & 8.22 & -25.54 \\
\hline Intestines, chiefly colon and rectum & $152-154,159.0$ & 3.43 & 4.94 & 43.91 & 4.20 & 4.44 & 5.78 \\
\hline Larynx & 161 & 2.94 & 2.92 & -0.58 & 0.86 & 0.50 & -42.49 \\
\hline Lung & 162 & 12.02 & 16.65 & 38.55 & 5.99 & 7.27 & 21.31 \\
\hline Breast & 174 & - & - & - & 11.17 & 20.71 & 85.44 \\
\hline Uterus, cervix and corpus & $179-182$ & - & - & - & 39.16 & 29.52 & -24.61 \\
\hline Ovary and other uterine adnexa & 183 & - & - & - & 3.69 & 6.40 & 73.45 \\
\hline Prostate & 185 & 3.19 & 5.38 & 68.76 & - & - & - \\
\hline Testis & 186 & 0.48 & 0.72 & 51.01 & - & - & - \\
\hline Bladder & 188 & 0.85 & 1.21 & 42.14 & 0.47 & 0.53 & 10.83 \\
\hline Leukaemias & $204-208$ & 2.57 & 3.97 & 54.21 & 2.52 & 3.67 & 45.71 \\
\hline All neoplasms, benign and malignant & $140-239$ & 76.05 & 93.72 & 23.23 & 126.47 & 125.76 & -0.57 \\
\hline
\end{tabular}

Between 1970-74 and 1995-99 it changed from 0.75 to $0.66 / 100000$ in women of all ages, and from 1.01 to $0.77 / 100000$ in middle-aged women.

Stomach cancer mortality rates in men showed a steady downward trend from the beginning of the 1970s to the late 1990s, changing from $9.90 / 100000$ in $1970-74$ to 9.17/100000 in 1995-99. Corresponding values for the truncated age group were 13.01 and 10.82/100000. Stomach cancer rates in women declined from $8.70 / 100000$ in 1970-74 to 6.58/100000 in 1995-99 for women of all ages, and from 11.04 to $8.22 / 100000$ in middle-aged ones.

Rates for intestinal cancer showed inconsistent patterns over time for both sexes, with a downward trend until the beginning of the 1980s and an upward one thereafter. Rates, however, were very low, i.e. $<5 / 100000$ for both sexes and all age groups.

Laryngeal cancer rates for men rose from 2.05/100000 in $1970-74$ to $2.58 / 100000$ in $1990-94$, and then levelled off to 2.44/100 000 in 1995-99. In middle-aged men, rates remained stable at around 3/100000. In women, rates were much lower than in men, and showed a downward trend over time, with both overall and truncated rates reaching a value of $\sim 0.50 / 100000$ in 1995-99.

Overall mortality from lung cancer in men showed a strong rising trend until the end of the 1980s (from 8.14/100000 in $1970-74$ to $15.92 / 100000$ in 1985-89), and then stabilised (15.55/100000 in 1995-99). In middle-aged men, after an increase until the late $1980 \mathrm{~s}$, lung cancer rates declined to $16.65 / 100000$ in 1995-99. Rates for lung cancer mortality in women were much lower than in men, but showed a steady upward trend. In women of all ages, they varied from $4.05 / 100000$ in $1970-74$ to $5.84 / 100000$ in $1985-89$ and
5.99/100000 for 1995-99; in middle-aged women, these rates rose from $5.99 / 100000$ in $1970-74$, to $7.69 / 100000$ in 1985-89 and 7.27/100000 in 1995-99.

Female breast cancer mortality showed a marked upward trend, particularly among women aged 34-64 years, who also showed much higher absolute values. It rose to $9.65 / 100000$ in women of all ages and to 20.71/100000 in middle-aged women.

Mortality rates from uterine cancers showed a decreasing trend. They dropped from $19.09 / 100000$ in $1970-74$ to $15.35 / 100000$ in 1995-99 for women of all ages, and from $39.16 / 100000$ to $29.52 / 100000$ in middle-aged ones, when most deaths are due to cervical cancer.

Data for ovarian cancer were available only for the years 1971-74 and 1997-99. Between these two periods, mortality increased from 1.81 to $3.41 / 100000$ in women of all ages, and from 3.69 to $6.40 / 100000$ in middle-aged women.

Total mortality from prostate cancer rose steadily during the period studied, with rates increasing from 5.47/100000 in $1970-74$ to $12.24 / 100000$ in 1995-99. In the truncated age group, rates were much lower and showed a less marked increasing trend, with variation from 3.19/100 000 in 1970-74 to $5.38 / 100000$ in $1995-99$.

Overall testicular cancer mortality rates were 0.38/100000 in 1971-74 and $0.68 / 100000$ in 1997-99; corresponding rates for middle-aged men were 0.48 and $0.72 / 100000$.

Bladder cancer mortality rates in men rose during the 1970 s and levelled off thereafter to a value of 1.42/100000 in 199599 for men of all ages, and to 1.21/100000 for middle-aged men. In women, rates were lower and increasing trends were smaller, but steady throughout the whole period studied. 

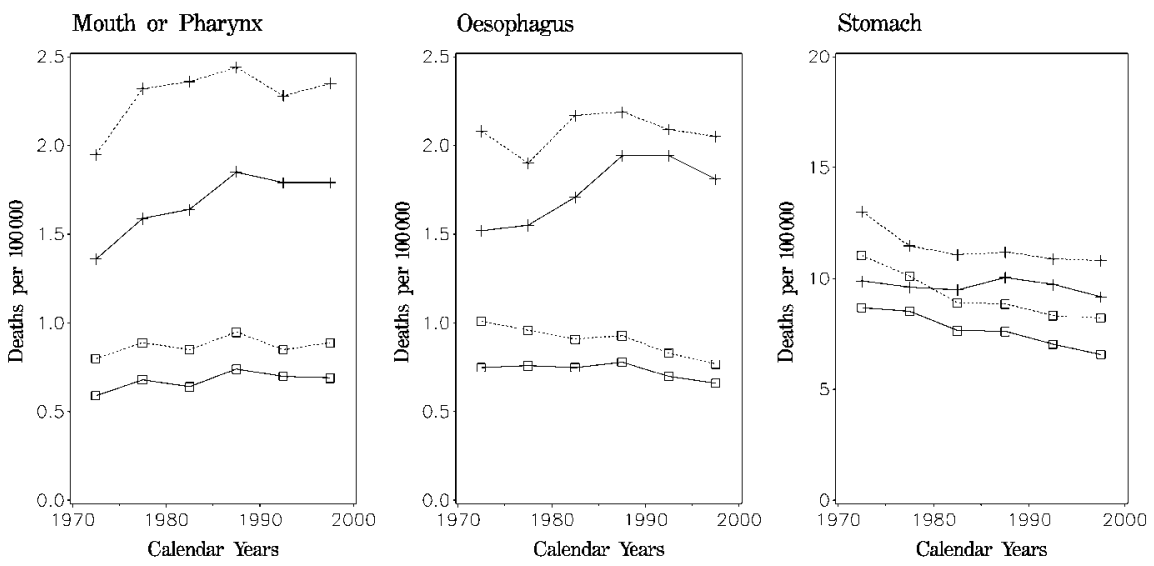

Intestines, Chiefly Colon \& Rectum
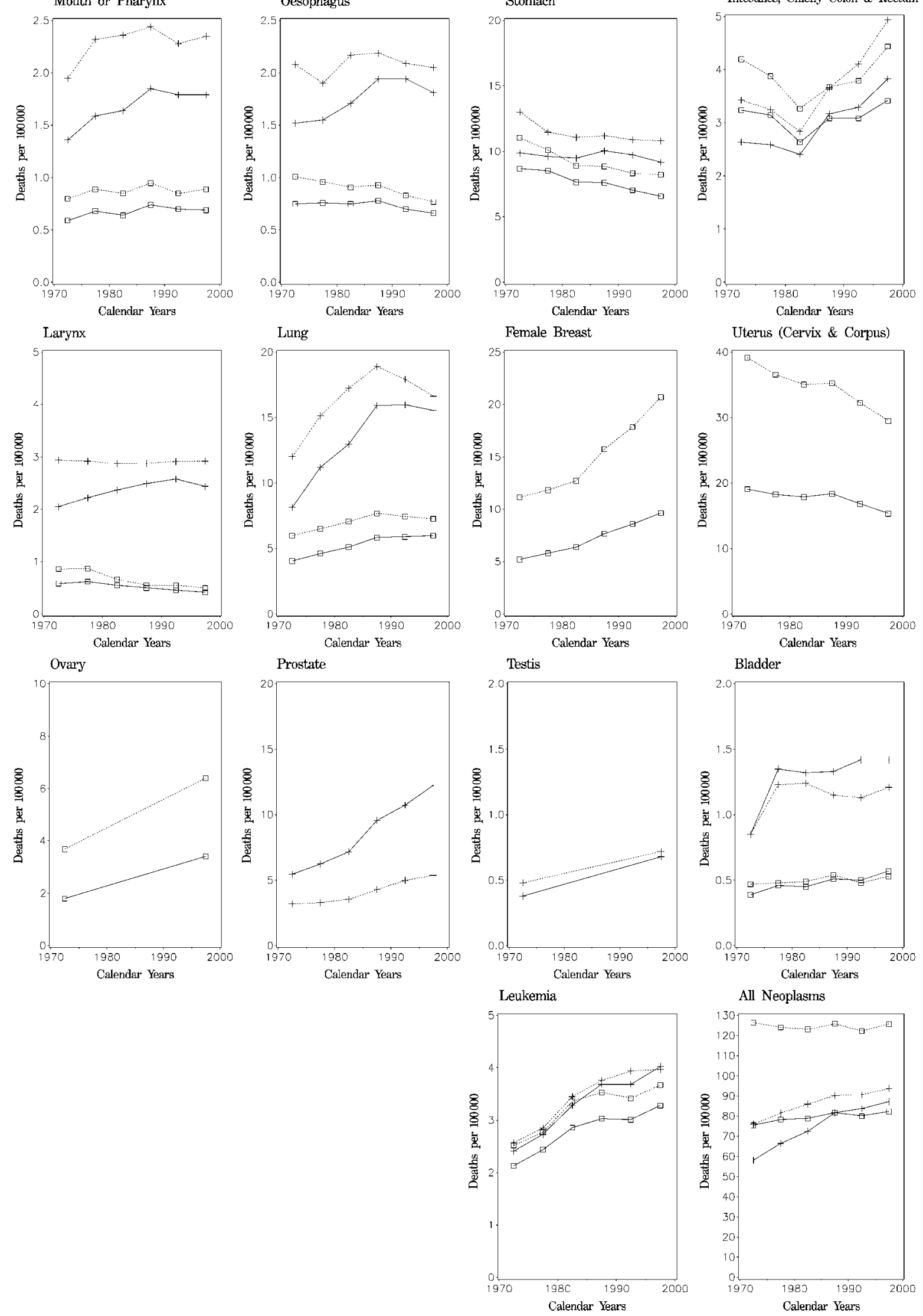

Figure 1. Trends in age-standardised (world population) death rates from major cancer sites and total cancer mortality in Mexico, 1970-99. Men, all ages solid lines/crosses; men, 35-64 years broken lines/crosses; women solid lines/squares, all ages; women, 35-64 years broken lines/squares. 
Rates for leukaemias showed a rising trend for both sexes. For men, overall rates rose from $2.41 / 100000$ in $1970-74$ to 4.03/100 000 in 1995-99, while truncated rates rose from 2.57 to $3.97 / 100000$, respectively. They rose from $2.13 / 100000$ in $1970-74$ to $3.28 / 100000$ in $1995-99$ for women of all ages, and from 2.52 to $3.67 / 100000$ for middle-aged women.

Mortality rates for all neoplasms (benign and malignant) showed a rising trend for men of all ages (from 58.18/100 000 in $1970-74$ to $87.14 / 100000$ in $1995-99$ ), and for middleaged men (from 76.05 to $93.72 / 100000$, respectively). In women, overall mortality rates showed a slight increase from the early $1970 \mathrm{~s}(75.43 / 100000)$ to the late $1990 \mathrm{~s}$ (82.28/100000); truncated rates were stable (126.47/100000 in 1970-74 and 125.76/100000 in 1995-99), although they were much higher than overall mortality, reflecting exceedingly high rates for uterine (mainly cervical) cancer mortality in middle-aged women.

\section{Discussion}

When interpreting trends in cancer mortality, it is important to consider the problems of death certification reliability and validity [23, 24]. In general, for several common cancer sites including lung, stomach and breast, death certification is sufficiently reliable to permit meaningful inference with respect to trends [4]. Greater caution is required for the few cancer sites whose diagnosis and certification may be largely influenced by the greater availability and utilisation of diagnostic techniques, and by the increased accuracy of death certification, including, among others, those of the colorectum, liver, bone, soft tissue sarcomas, prostate, myelomas and other lymphoid neoplasms. Some of these cancers, involving major difficulties in diagnosis and certification, were excluded from the present analyses (i.e. liver, bone, skin, sarcomas and myelomas).

The present updated analysis indicates that cancer mortality in Mexico has remained comparably low on a worldwide scale [1], although a moderate upward trend in total cancer mortality has been observed during the last three decades, particularly in men. This reflects the patterns for various major cancer sites, such as the earlier rises in lung and other tobacco-related neoplasms, as well as those for breast and prostate cancer.

Mortality rates for cancers of the mouth and pharynx, oesophagus and larynx were low in Mexico for both sexes, as compared with most American and European countries [1]. The pattern in trends in men was, however, consistent with that observed in several European countries [25], with increasing rates until the mid-1980s and a tendency to decrease thereafter. No major trends over time were shown in women, whose rates were remarkably low. Since all these neoplasms are strongly related to tobacco and alcohol consumption [26], recent trends in mortality suggest a change in the exposure to these two major risk factors over the last decade, particularly in Mexican men, although consumption data are only available for tobacco [27]. The average annual number of cigarettes per adult, based on sale data, decreased from 1600 in
1970-72 to 970 in 1990-92, although there are uncertainties surrounding these figures. According to a national interviewbased survey, the prevalence of current smokers among urban residents decreased from $43.6 \%$ to $38.3 \%$ in men, and from $16.0 \%$ to $14.4 \%$ in women between 1971 and 1990 [27]. Additional factors, mainly related to diet, may also have had some effect on recent trends of upper digestive and respiratory tract neoplasms [28], although no analytical data exist on the association between diet and these cancers in the Mexican population.

As in most developed and developing countries, stomach cancer rates have been steadily and appreciably declining in Mexico for both sexes over the last few decades. In the late 1990s, Mexican gastric cancer rates were still more than twofold higher than those of the United States [1], but comparable to those observed in several European countries [25]. The fall in gastric cancer is generally attributed to a more varied and affluent diet [29], together with improvements in food storage and conservation, including refrigeration [30], and a decline in Helicobacter pylori infection [31].

All intestinal cancers were combined in our analyses, since the distinction between colon and rectum may pose some problems (several cancers arise in the recto-sigmoid junction $[20,32]$ ), and a large proportion of colorectal cancer deaths are classified as 'intestines, site of origin unspecified' (ICD IX 159,0). Mortality from cancer of the colorectum showed discontinuous trends over the three decades considered, with a sudden fall between 1970 and 1985 and a subsequent rise, which could be related to changes in diagnosis and certification criteria, such as the classification of other and non-specified digestive tract neoplasms. These difficulties notwithstanding, and despite a recent rise in mortality, intestinal cancer rates remain exceedingly low in Mexico compared with other countries in North America and Europe, as well as in Latin America [4]. This could essentially be related to the Mexican diet, including its high fibre and vegetable content, which has been changing over recent decades [33]. A deeper understanding of the real Mexican colorectal mortality rates and their potential determinants would be of major relevance for colorectal cancer control in other countries, too.

The rise in male lung cancer mortality between the 1970s and the early 1990s, and the subsequent levelling off in all men, and decline in middle-aged men, are of specific interest since they indicate that young and middle-aged Mexican men have been less frequently smokers over recent decades [27]. In particular, the recent trends in the truncated age group indicate that overall lung cancer rates are unlikely to rise substantially in the near future. On an absolute level, lung cancer rates in Mexican men are appreciably lower than those registered in North America or most European countries [1]. For women, the moderate upward trends in lung mortality rates over the last decade, together with the persisting low absolute values of lung cancer mortality (i.e. less than one-quarter of those in the United States), indicate that a major epidemic of lung cancer is unlikely to occur in the near future. These favourable trends notwithstanding, lung cancer is one of 
the leading causes of death in Mexico [34], and prevention of tobacco use remains a major public health priority in this population.

Although breast cancer rates in Mexico remain at relatively low levels compared with North America or Europe [1], they have been rising steadily over the last three decades. The increase is likely to be related to changes in the reproductive habits of subsequent cohorts of Mexican women, and in particular to decreased fertility in several Mexican states in recent decades [8]. The use of exogenous hormones, as well as the increased prevalence of obesity [35] and dietary factors [36], may also have played a role in the recent upward trend in breast cancer mortality. In the absence of the effective adoption of screening, and of therapeutic advantage treatments breast cancer mortality in Mexico is likely to increase further in the near future [37].

On the basis of death certification it was not possible to distinguish cancers arising from the cervix and the corpus uteri (endometrium), since a substantial proportion of deaths from uterine cancer are attributed to 'uterus unspecified'. However, since endometrial cancer mortality is rare in young women, trends in young and middle-aged women are largely due to cervical cancer. Uterine cancer rates were exceedingly high in Mexico, accounting for almost one in six of all cancer deaths in women. This is essentially due to high rates of cervical cancer, as also indicated by the high mortality in young and middle-aged women. Although a decline of $>30 \%$ in uterine cancer mortality in middle-aged women has been observed over the last three decades, the truncated rate of 29.3/100000 in 1999 was still more than three-fold higher than in the European Union [25] and North America, and also higher than in most other Latin American countries [5]. This essentially reflects the inadequate utilisation of cervical screening [38-40], the implementation of which therefore remains a priority with respect to cancer control among Mexican women.

Ovarian cancer rates were approximately two-fold higher in 1999 compared with 1971, although they remained comparably low on an international scale [1]. As for breast cancer, the upward trends in ovarian cancer rates can be related to the declined parity of subsequent generations of Mexican women, although modifications to dietary and other lifestyle factors may also have played some role in changing ovarian cancer mortality rates [41].

Overall, prostate cancer rates have increased by $>140 \%$ during the last three decades, approaching levels comparable to those of North America and several European countries $[1,22]$. The rising trend was smaller in the truncated rates, suggesting that recent changes and improvements in diagnosis and certification are likely to have played a major role in the trends registered [42].

Rates for cancer of the testis were higher in 1998-99 than in 1971. This probably reflects a real increase in the incidence, together with inadequate adoption of modern platinum-based chemotherapy regimens, which have substantially reduced mortality from testicular cancer in developed areas of the world [43].
Bladder cancer mortality increased appreciably in men in the early 1970s, but levelled off thereafter to relatively low rates on a worldwide scale. These trends were consistent with those observed for lung and other tobacco-related cancers, and consequently with a decrease in tobacco consumption in recent decades [27], as tobacco is the single major recognised risk factor for bladder cancer on a population level [44].

Mortality from leukaemias showed a rising trend for both sexes, in contrast to a tendency to decline in most developed areas of the world over recent decades following the adoption of integrated therapy regimens, mainly in children and young adults [45]. As for testicular cancer, this would suggest some delay in the adoption of modern effective therapy schemes, although Mexican mortality rates for leukaemias remain relatively low on a worldwide scale [1]. It is, however, possible that these trends were also influenced by the improved accuracy of diagnosis and certification [20].

In conclusion, although the increasing trends in mortality for lung and other tobacco-related neoplasms have tended to level off in Mexico over the last decade, steady rises have been observed for other major cancers, including breast and prostate. Uterine (mainly cervical) cancer remains a major health problem in Mexican women, with declines appreciably lower than those reported in the United States and Europe [25], and still very high mortality rates on a worldwide scale. Favourable trends in cancer mortality in Mexico in the near future would therefore require an integrated strategy of prevention focused on control of tobacco and other lifestyle risk factors, as well as on early diagnosis, mainly for cervical cancer, and the adoption of therapeutic advancements for selected neoplasms amenable to treatment.

\section{Acknowledgements}

The authors wish to thank Mrs M. P. Bonifacino for editorial assistance. This work was conducted with funding from the Italian Association for Cancer Research, and the Italian and Swiss Leagues Against Cancer. Dr T. Rodríguez was supported by an AECI (Spanish Agency of International Cooperation) fellowship.

\section{References}

1. Levi F, Lucchini F, Negri E, La Vecchia C. Worldwide patterns of cancer mortality, 1990-94. Eur J Cancer Prev 1999; 8: 381-400.

2. Instituto Nacional de Estadística, Geografia e Informatica (INEGI). XII Censo General de Población y Vivienda, Mexico, 2000.

3. Dirección General de Estadística e Informática/INEGI. Estadísticas en Salud: Mortalidad. México, DF: Secretaría de Salud 1999.

4. La Vecchia C, Lucchini F, Negri E et al. Trends in cancer mortality in the Americas, 1955-1989. Eur J Cancer 1993; 29A: 431-470.

5. Bocciolone L, La Vecchia C, Levi F et al. Trends in uterine cancer mortality in the Americas, 1955-1988. Gynecol Oncol 1993; 51: $335-344$.

6. Boffetta P, La Vecchia C, Levi F, Lucchini F. Mortality patterns and trends for lung cancer and other tobacco-related cancers in the Americas, 1955-1989. Int J Epidemiol 1993; 22: 377-384.

7. Lazcano-Ponce EC, Tovar Guzman V, Meneses Gonzalez F et al. Trends of lung cancer mortality in Mexico. Arch Med Res 1997; 28 : $565-570$. 
8. Lopez-Rios O, Lazcano-Ponce EC, Tovar-Guzman V, HernandezAvila M. Epidemiology of cancer of the breast in Mexico. Consequences of demography transition. Salud Publica Mex 1997; 39: $259-265$.

9. Tovar-Guzman V, Flores-Aldana M, Salmeron-Castro J, LazcanoPonce EC. Epidemiologic panorama of colorectal cancer in Mexico, 1980-1993. Dis Colon Rectum 1998; 41: 225-231.

10. Tovar-Guzman V, Hernandez-Giron C, Lopez-Rios O, Lazcano-Ponce EC. Prostate cancer mortality trends in Mexico, 1980-1995. Prostate 1999; 39: 23-27.

11. Tovar-Guzman V, Hernandez-Giron C, Barquera S et al. Epidemiologic panorama of stomach cancer mortality in Mexico. Arch Med Res 2001; 32: 312-317.

12. Escandon-Romero C, Benitez-Martinez MG, Navarrete-Espinoza J et al. Epidemiology of cervical cancer at the Mexican Institute of Social Security. Salud Publica Mex 1992; 34: 607-614.

13. Lazcano-Ponce EC, Rascon-Pacheco RA, Lozano-Ascencio R, Velasco-Mondragon HE. Mortality for cervical carcinoma in Mexico: impact of screening, 1980-1990. Acta Cytol 1996; 40: 506-512.

14. Robles SC, White F, Peruga A. Trends in cervical cancer mortality in the Americas. Bull Pan Am Health Organ 1996; 30: 290-301.

15. WHO Statistical Information System (WHOSIS). WHO Mortality Database. Geneva: WHO 2003; http://www3.who.int/whosis (18 February 2004, date last accessed).

16. WHO. International Classification of Disease: 8th Revision. Geneva: WHO 1967.

17. WHO. International Classification of Disease: 9th Revision. Geneva: WHO 1977.

18. WHO. International Statistical Classification of Disease and Related Health Problems: 10th Revision. Geneva: WHO 1992.

19. La Vecchia C, Lucchini F, Negri E et al. Trends in cancer mortality in Europe, 1955-1989: I, digestive sites. Eur J Cancer 1992; 28: 132-235.

20. Doll R, Peto R. The causes of cancer: quantitative estimates of avoidable risks of cancer in the United States today. J Natl Cancer Inst 1981; 66: 1191-1308.

21. Pan American Health Organization (PAHO). Special Program for Health, Technical Information System. Regional Mortality Database 2001; http://www.paho.org (28 February 2003, date last accessed).

22. Doll R, Smith PG. Comparison between registries: age-standardized rates. In Waterhouse JAH, Muir CS, Shanmugaratnam K et al. (eds): Cancer Incidence in Five Continents, Vol. IV. Lyon: IARC Sci Publ 1982, No. 42; 671-675.

23. Percy C, Staneck E, Gloeckler L. Accuracy of cancer death certification and its effects on mortality statistics. Am J Publ Health 1981; 71: 242-250.

24. Boyle P. Relative value of incidence and mortality data in cancer research. Recent Results Cancer Res 1989; 114: 41-63.

25. Levi F, Lucchini F, Negri E et al. Cancer mortality in Europe, 19951999, and an overview of trends since 1960. Int J Cancer 2004; 110: $155-169$.
26. Franceschi S, Talamini R, Barra S et al. Smoking and drinking in relation to cancers of the oral cavity, pharynx, larynx and esophagus in Northern Italy. Cancer Res 1990; 50: 6502-6507.

27. WHO. Tobacco or Health. A Global Status Report. Geneva: WHO 1997.

28. La Vecchia C, Tavani A, Franceschi S, Levi F et al. Epidemiology and prevention of oral cancer. Oral Oncol 1997; 33: 302-312.

29. Lopez-Carrillo L, Lopez-Cervantes M, Ward MH et al. Nutrient intake and gastric cancer in Mexico. Int J Cancer 1999; 83: 601-605.

30. La Vecchia C, Franceschi S. Nutrition and gastric cancer with a focus on Europe. Eur J Cancer Prev 2000; 9: 291-295.

31. Munoz N. Is Helicobacter pylori a cause of gastric cancer? An appraisal of the seroepidemiologic evidence. Cancer Epidemiol Biomarkers Prev 1994; 3: 445-451.

32. Boyle P, Zaridze DG, Smans M. Descriptive epidemiology of colorectal cancer. Int J Cancer 1985; 36: 9-18.

33. Parra-Cabrera S, Fernandez-Ortega MC, Vandale-Toney S, LopezCarrillo L. Dietary fiber and gastro-intestinal tumors, implications for the Mexican population. Arch Latinoam Nutr 1994; 44: 76-81.

34. Centers for Disease Control and Prevention (CDC). Smoking attributable mortality: Mexico, 1992. JAMA 1995; 274: 208-209.

35. Aguilar-Salinas CA, Vazquez-Chavez C, Gamboa-Marrufo R et al. Obesity, diabetes, hypertension, and tobacco consumption in an urban adult Mexican population. Arch Med Res 2001; 32: 446-453.

36. Bonilla-Fernández $\mathrm{P}$, López Cervantes $\mathrm{M}$, Torres-Sánchez LE et al. Nutritional factors and breast cancer in Mexico. Nutr Cancer 2003; 45: 148-155.

37. Tarone RE, Chu KC, Gaudette LA. Birth cohort and calendar period trends in breast cancer mortality in the United States and Canada. J Natl Cancer Inst 1997; 89: 251-256.

38. Watkins MM, Gabali C, Winkleby M, Gaona E et al. Barriers to cervical cancer screening in rural Mexico. Int J Gynecol Cancer 2002; 12: $475-479$.

39. Lazcano-Ponce EC, Buiatti E, Najera-Aguillar A et al. Evaluation model of the Mexican national program for early cervical cancer detection and proposals for a new approach. Cancer Causes Control 1998; 9: 241-251.

40. Hernandez-Avila M, Lazcano-Ponce EC, de Ruiz PA, Romieu I. Evaluation of the cervical cancer screening programme in Mexico: a population-based case-control study. Int J Epidemiol 1998; 27: $370-376$.

41. La Vecchia C. Epidemiology of ovarian cancer: a summary review. Eur J Cancer Prev 2001; 10: 125-129.

42. Boyle P. Prostate cancer: creation and control of an epidemic. J Epidemiol Biostat 1996; 1: 65-67.

43. Levi F, Lucchini F, Boyle $P$ et al. Testicular cancer mortality in eastern Europe. Int J Cancer 2003; 105: 574.

44. Negri E, La Vecchia C. Epidemiology and prevention of bladder cancer. Eur J Cancer Prev 2001; 10: 7-14.

45. Pui CH, Evans WE. Acute lymphoblastic leukemia. N Engl J Med 1998; 339: 605-615. 